\section{Empresa Brasileira de Serviços Hospitalares: um novo modelo de gestão?}

\author{
Empresa Brasileira de Serviços \\ Hospitalares (The Brazilian \\ Company of Hospital Services): \\ a new management model?
}

guns esclarecimentos, inclusive no aspecto jurídico, no intuito de embasar e iniciar um diálogo sobre o tema.

Palavras-chave: Saúde pública. Gestão. Hospital Universitário Federal.

Abstract: This article have the goal to present the panorama that the federal university hospitals are - inserted in the historical context affected by the productivist logic, state reform and precarization of the work relations and conditions. Was tried here to make a path of this institutions until the present moment, with the movement of the federal government to transfer the management to third parties (public companies under private law). Lastly, from the many questions that were raised with this "new" management proposal, follows some clarifications, inclusive in the law aspect, with the intention to base and start a dialog about the theme.

Keywords: Public Health. Management. Federal University Hospital.

Resumo: Este artigo tem por objetivo apresentar o panorama em que se encontram os hospitais universitários federais - inseridos em um contexto histórico marcado pela lógica produtivista, reforma do Estado e precarização das condições e relações de trabalho. Tentou-se aqui traçar o caminho dessas instituições até o momento atual, com o movimento do governo federal de repassar a gestão destes hospitais a terceiros (empresa pública de direito privado). Por fim, a partir dos inúmeros questionamentos surgidos com essa "nova" proposta de gestão, seguem al-

* Assistente social, doutora em Saúde Coletiva. Docente do Departamento de Serviço Social e Programa de Pós Graduação em Saúde Coletiva da UFES - Espírito Santo, Brasil.E-mail: francisodre@uol.com.br.

** Assistente social, mestre em Saúde Coletiva pela UFES. E-mail: denildalittike@yahoo.com.br.

***Assistente social, mestre em Política Social pela UFES.E-mail: leandraborlini@hotmail.com.

**** Promotora de Justiça, mestre em Saúde Coletiva pela UFES.E-mail: mperim@mpes.gov.br.

\section{Introdução}

No Brasil, os hospitais universitários federais (HUFs) têm por finalidade exercer o ensino, a pesquisa e a extensão, por meio da assistência à saúde. São responsáveis por grande parte das pesquisas clínicas na área biomédica e pela formação de um expressivo número de profissionais de saúde, em nível de graduação e pós-graduação (Reis e Cecílio, 2009). São instituições cuja gestão está subordinada à Universidade Federal da qual corresponde, ao Ministério da Educação e Cultura (MEC) por sua frente de ensino, e ao Ministério da Saúde (MS) pela vinculação ao sistema de saúde pública. 
Os HUFs exercem um papel político importante na comunidade inserida, visto sua escala, dimensionamento e custos projetados a partir da alta concentração de recursos humanos, físicos e financeiros (Médici, 2001). Representam 2,55\% da rede hospitalar brasileira, $10,3 \%$ dos leitos do SUS, $25,6 \%$ dos leitos de UTI, $50 \%$ das cirurgias cardíacas e neurológicas, e 70\% dos transplantes (Lopez, 2005).

A partir da década de 1990, os HUFs inserem-se na rede de saúde pública e passam a ser remunerados pelo Ministério da Saúde (Reis e Cecílio, 2009). ${ }^{1}$ A "parceria" entre o SUS e os HUFs está prevista no artigo 45 da Lei Orgânica da Saúde (LOS). ${ }^{2}$

Art. 45. Os serviços de saúde dos hospitais universitários e de ensino integram-se ao Sistema Único de Saúde (SUS), mediante convênio, preservada a sua autonomia administrativa, em relação ao patrimônio, aos recursos humanos e financeiros, ensino, pesquisa e extensão nos limites conferidos pelas instituições a que estejam vinculados. (Brasil, 1990; grifos nossos)

O Brasil possui espalhado em seu território o total de 46 HUFs (Brasil, 2009b), os quais agregam as políticas de educação e saúde. Em linhas gerais, o MEC é res-

1. A inserção dos HUFs na rede assistencial da saúde pública foi abordada em Drago (2011).

2. É necessário destacar que os hospitais universitários são vinculados a escolas ou universidades. Estas, por sua vez, são ligadas ao MEC. A inserção dos hospitais ao SUS se dá por "necessidade" da rede ou do próprio hospital no que tange recursos e meios para a execução das práticas. ponsável pela despesa de pessoal dessas instituições, enquanto ao MS cabe os valores repassados mediante pactuação de metas (quantitativas e qualitativas) com o governo federal e estadual. Ainda que os HUFs não pertençam ao sistema de saúde do estado de referência, ele está inserido nesse sistema e pactua a partir disso as suas metas de prestação de serviços — não sem considerar a sua função primária de formação e pesquisa, o que o torna duplamente complexo.

Atualmente, os HUFs apresentam quadros de servidores insuficientes, instalações físicas deficientes e subutilização da capacidade instalada para alta complexidade, reduzindo assim a oferta de serviços à comunidade. Essa conjuntura tem implicado fechamento de leitos e serviços, bem como em contratações de mão de obra terceirizada (situação considerada ilegal pelo Tribunal de Contas da União). Dados do MEC mostram que em 2008, 1.124 leitos foram desativados nessas instituições sob a justificativa de escassez do quadro de pessoal. Com um déficit, desde 2008, de 5.443 servidores, a questão dos recursos humanos dos hospitais se agrava com a perspectiva de aposentadoria de 3.741 servidores, entre 2008 e 2010 , dos quais 996 são auxiliares e técnicos de enfermagem, 319 enfermeiros e 370 médicos (Brasil, 2009a).

Cabe destacar que a deficiência ou mesmo a ausência de profissionais nos hospitais universitários é um reflexo da junção de vários fatores: a ausência de concursos por parte do MEC; a não responsabilização do MS pela mão de obra 
desses hospitais no que tange à assistência; a defasagem dos salários oferecidos, o que gera a busca por outros vínculos; a pressão das entidades de controle, como o TCU, proibindo a contratação direta por parte dos hospitais; o não planejamento do governo para o momento atual que demarca elevado número de aposentadorias, ou seja, não houve e não há uma política de reposição desses funcionários de forma a manter o equilíbrio no quadro de pessoal; e o nível de adoecimento e consequente afastamento dos funcionários (Ribeiro et al., 2010).

Além do contingente de servidores, importa caracterizar a precarização das relações de trabalho (Figura 1). Calcula-se que cerca de $48 \%$ dos profissionais lota- dos nos HUFs estão sob regimes precários e/ou desregulamentados. Há nos HUFs profissionais contratados por tempo determinado de serviço pela própria universidade ou via fundações, serviços terceirizados (sobretudo em áreas de higienização, segurança, transporte e nutrição), prestação de serviços mediante Recibo de Pagamento a Autônomo (RPA) ou ainda Solicitação de Serviço de Pessoa Externa (SSPE). A insuficiência de pessoal e/ou grande rotatividade dos vínculos contribui significativamente para a ineficiência dos serviços, a consequente precariedade da instituição e a fomentação de impasses entre os próprios trabalhadores diante dos diferentes salários, benefícios e carga horária, conforme o vínculo.

Figura 1 - Força de trabalho dos HUFs

Total: $\mathbf{6 6 . 8 4 3}$

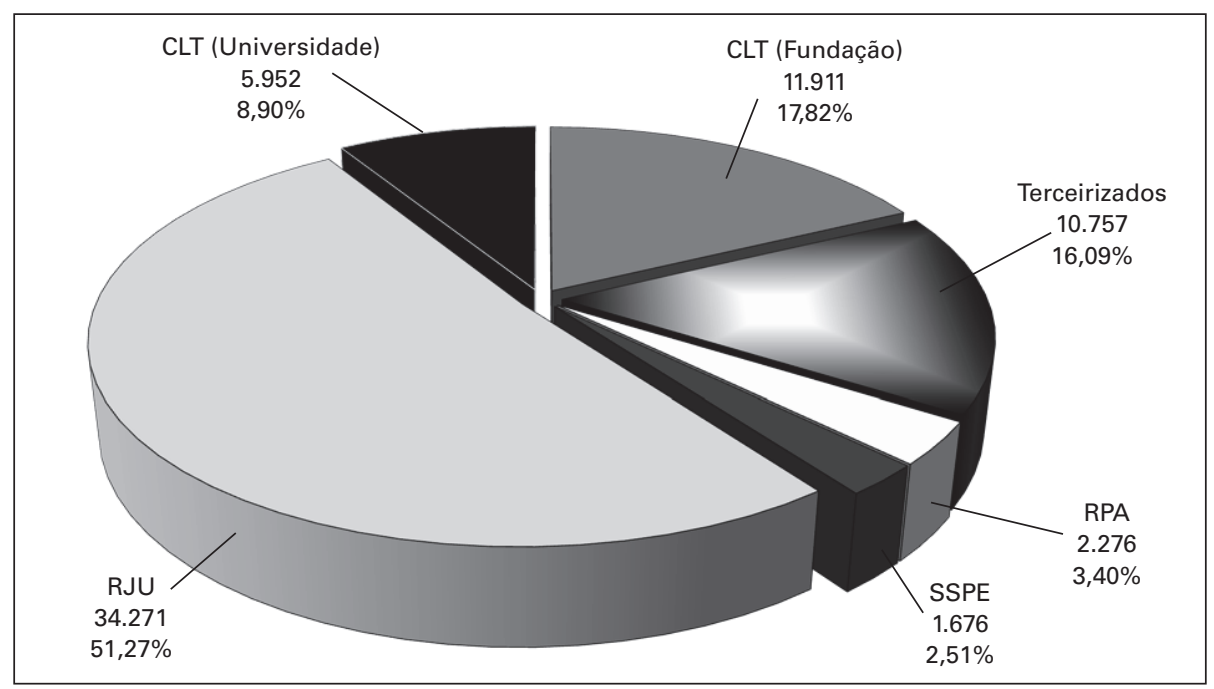

Fonte: Brasil, 2009b. 
A multiplicidade de vínculos aqui apresentada gera reflexos nos processos de trabalho, seja no aspecto legal dessas contratações, seja nas diferentes relações entre empregado e empregador: força sindical, remuneração, carga horária e outros benefícios. Isso tem gerado desigualdades entre os trabalhadores da mesma categoria, inseridos na mesma instituição. Segundo Machado (2005, p. 272).

O processo de trabalho e o mundo do trabalho estão se transformando de forma significativa, alterando a modalidade de inserção e os vínculos empregatícios, a forma de remuneração e, muito fortemente, o modo de trabalhar, configurando-se em arenas competitivas, individualizadas e em ambientes pouco saudáveis.

No aspecto jurídico, os HUFs têm sido pressionados pelos órgãos de controle social - TCU (Tribunal de Contas da União), CGU (Controladoria Geral da União) e MPF (Ministério Público Federal) - a regularizar a situação do quadro funcional por meio de concursos públicos. Todavia, o Ministério do Planejamento, Orçamento e Gestão (MPOG), sob a justificativa de déficit financeiro, tem resistido a essa determinação.

Por trás da diversificada composição da força de trabalho nos HUFs, encontra-se uma das fontes para o alto nível de endividamento dessas instituições (Cislaghi, 2010). Isso ocorre porque os quase $50 \%$ do total de funcionários não são regidos pelo Regime Jurídico da União (RJU), ou seja, não pertencem ao quadro de servidores estatutários do MEC, e, portanto, são custeados por recursos do próprio hospital em que laboram. Dessa forma, grande parcela dos recursos financeiros que deveriam ser investidos no ensino, na pesquisa, na extensão e na assistência é transformada em folha de pagamento de pessoal terceirizado (Carmo, 2006).

Segundo Pillotto [2008?], dados da Associação Nacional dos Diretores de Instituições Federais de Ensino Superior (Andifes) mostram que em 2007 quase $45 \%$ do financiamento era usado para pagamento de pessoal terceirizado e já eram necessárias 5 mil novas vagas para quadro técnico-administrativo. Por outro lado, ocorre a diminuição do financiamento via governo federal, ${ }^{3}$ resultando na busca dos HUFs por mais dinheiro via SUS, assumindo para isso metas nem sempre possíveis de serem cumpridas. Começa também a busca de financiamento por meio de doações e parcerias (Amigos do HU, por exemplo).

O MEC aponta que somente os HUFs acumulam um déficit total de R\$ 30 milhões/ano (diferença entre o produzido e o pago), resultante também dos valores defasados da tabela SUS, levando a uma dívida acumulada de R $\$ 425$ milhões (Figura 2). Este valor equivale a mais do que todo o recurso alocado pelo Banco Mundial para o Rehuf (Cislaghi, 2010).

3. Para a Andifes, a dívida dos hospitais seria, em 2003, de R\$303 milhões, e para o MEC/MS seria de R\$ 230 milhões. Segundo a Andifes, em outubro de 2007 os Hospitais vivem uma situação de "equilíbrio estável" com a dívida chegando a R\$ 440 milhões. É sempre válido lembrar que em 2007 os gastos governamentais com a dívida pública, externa e interna, foram de $\mathrm{R} \$ 237$ bilhões. No mesmo ano, o investimento em saúde foi de R\$ 40 bilhões (Pilloto, [2008?]). 


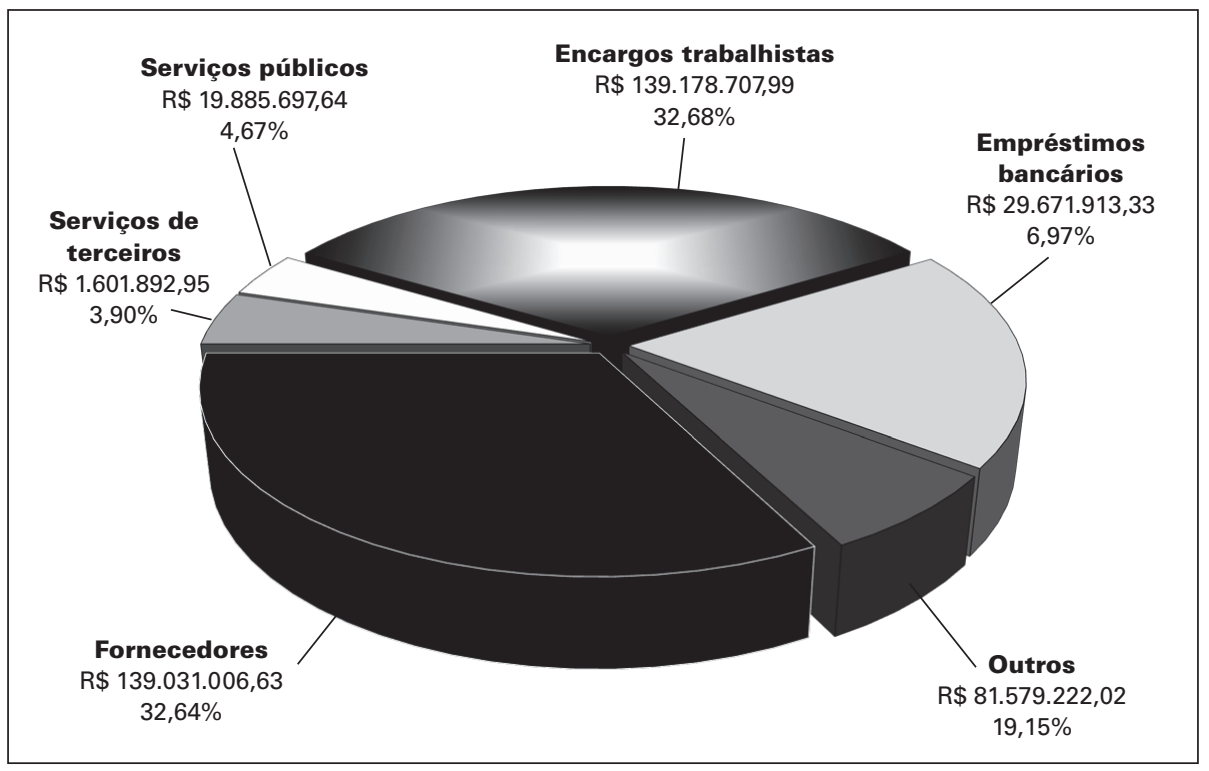

Fonte: Brasil, 2009a.

Perpassa por esse quadro uma importante característica dos HUFs: a gestão por meio da improvisação. Isso fica evidente na diversidade dos vínculos trabalhistas, bem como na gestão dos recursos materiais e na ausência de espaços coletivos e permanentes para o planejamento das ações a serem realizadas nessa complexa instituição hospitalar (Littike, 2012).

Reconhece-se que os HUFs não têm autonomia para abertura de concurso público para a admissão de servidores estatutários e que para tal dependem da anuência do governo federal. Contudo, de acordo com Cecílio (2002), nem todos os problemas de um hospital resultam da baixa autonomia para a obtenção de recursos financeiros, materiais e de pessoal. Para o autor, torna-se necessário fazer um melhor aproveitamento dos recursos existentes, pois estes sempre serão limitados. Silva (2004) aponta que os principais entraves da gestão em saúde não se limitam a recursos financeiros e materiais, mas sim, nesta área, a gestão deveria pautar-se em planejamento e avaliação de forma contínua.

Diante desse cenário, crescem as propostas de gestores locais e governantes políticos para a flexibilização da captação de recursos, ${ }^{4}$ como também para a des-

4. No ano de 2001, previa-se a venda de $25 \%$ dos leitos dos hospitais universitários. Essa privatização geraria ainda mais sucateamento para as áreas do hos- 
vinculação dos hospitais de ensino das universidades, visto que o Ministério da Educação não considera a "assistência" como sendo de sua responsabilidade. ${ }^{5}$

A "crise" instalada nos hospitais universitários abre precedentes para a aproximação voraz da privatização das áreas sociais de responsabilidade do Estado. A saúde e a educação pública têm perdido espaço para o mercado privado, diante de um discurso de ineficiência estatal, e se subordinam a ditames mercadológicos, em que a universalidade do direito (garantidos por lei na saúde e na educação) é substituída pela compra e venda de serviços.

A via de "salvação" dos HUFs - argumenta o governo federal desde a era Fernando Henrique Cardoso - seria a criação das fundações estatais de direito privado - como unidades gestoras dos hospitais -, defendidas inicialmente pelo Ministério do Planejamento, Orçamento e Gestão (MPOG) e, em seguida, pelo MS. ${ }^{7}$ Tais propostas foram rejeitadas pelas

pital que continuassem públicas. A proposta foi barrada depois de uma greve de mais de cem dias, organizada por trabalhadores técnico-administrativos, estudantes e docentes das universidades.

5. Essa proposta surgiu no Projeto de Lei n. 7.200/05, chamado de "Reforma Universitária".

6. Para Lima (2004) permanece uma "situação crônica", percebida de diferentes maneiras, nos HUFs que assume múltiplas dimensões: a organizacional, a do ensino, a assistencial, a política, a financeira e a social. Tais dimensões não são independentes entre si, mas sim interligadas, onde o sucesso ou o conflito em uma área reflete significativamente nas outras (Lopez, 2005).

7. Para os formuladores destas propostas, as áreas como saúde, previdência, educação, turismo e assistência social não são de responsabilidade exclusiva do Estado e, portanto, devem ser repassadas à gestão do mercado (Moñtano, 2002). entidades que se articulam na defesa do projeto histórico do SUS e expressas na $13^{\mathrm{a}}$ (2007) e $14^{\mathrm{a}}$ Conferência Nacional de Saúde (2011), que rejeitou por maioria de delegados a proposta da fundação estatal. Entretanto, permaneceu latente na conjuntura neoliberal a intenção de repasse da área social ao mercado (Drago, 2011).

Em 2010, para a continuidade de ações que regulamentam a reestruturação dos HUFs, foi elaborado o Decreto n. 7.082/2010, que instituiu o Programa Nacional de Reestruturação dos Hospitais Universitários Federais - Rehuf - o qual tem em seu texto o discurso de "criar condições materiais e institucionais para que os HUFs possam desempenhar plenamente suas funções na dimensão de ensino, pesquisa, extensão e também na assistência à saúde" (Brasil, 2010a). O decreto assinala as funções cabíveis aos ministérios envolvidos (MEC, MS e MPOG) e reforça as diretrizes sobre as quais o Rehuf está assentado, a saber:

- instituição de mecanismos adequados ao financiamento, progressivamente e igualmente compartilhados entre os ministérios da Saúde e Educação até 2012;

- melhorias no processo de gestão;

- adequação da estrutura física;

- recuperação do parque tecnológico;

- reestruturação do quadro de recursos humanos;

- aprimoramento das atividades, avaliação permanente das mesmas; e,

- incorporação de novas tecnologias no que se refere ao ensino, pesquisa e assistência. 
Observa-se que o financiamento dos hospitais de ensino é destaque no texto do Decreto n. 7.082 que estipula a partilha igualitária entre MEC e MS nas despesas dos HUFs, ${ }^{8}$ em que saúde e a educação necessitam de uma programação orçamentária, de forma a cumprir as parcelas cabíveis, respectivamente. Há nesta partilha a intencionalidade do MEC em reduzir sua participação no orçamento dos HUFs, ao mesmo tempo que seria ampliada a receita do MS. Subjaz aqui a intenção de esquiva das responsabilidades financeiras e/ou despesas, numa lógica em que a educação e a saúde são por demais dispendiosas ao governo.

Os discursos dos Ministérios da Saúde e da Educação apontam que o alcance dessa reestruturação requer alterações significativas no parque tecnológico, na estrutura física, no quadro de pessoal, no processo de avaliação e na participação de atores externos à instituição. Trata-se, assim, de mudanças consideráveis no processo de gestão dos HUFs, e para tanto será preciso uma "pactuação global" de metas entre ministérios da Saúde, Educação e Cultura, de Planejamento, Orçamento e Gestão (Brasil, 2010a). Há, portanto, nessa proposta, um redesenho dos hospitais universitários, em especial no aspecto finan-

8. O decreto estipula a progressão dos percentuais de cada ministério envolvido, até que em 2012 ambos contribuam de forma igual. Para fins de financiamento serão consideradas despesas dos HUFs o montante das despesas correntes alocadas para esses hospitais, bem como as custas para sua reestruturação e modernização, excluindo-se deste montante as despesas com inativos e aposentados (Brasil, 2010a). ceiro e na multiinstitucionalidade que os envolve. O Rehuf sugere, nas entrelinhas, uma alteração e um embate na discussão de quem é o dono do hospital universitário. Ao determinar a partilha entre MEC e MS, o governo aponta para um modelo de hospital escola, em que amplia o aspecto da assistência, enquanto reduz o papel da formação, do ensino e da pesquisa. $\mathrm{O}$ ensino mantém-se esfacelado enquanto a assistência é utilizada como moeda de troca (Drago, 2011).

Ainda na tentativa de redesenho dos hospitais universitários, o MEC junto ao MPOG, elaboram a Medida Provisória n. 520, assinada em 31 de dezembro de 2010, a qual autoriza o Poder Executivo a criar a Empresa Brasileira de Serviços Hospitalares S. A. (EBSERH), que tem, entre outras competências, administrar unidades hospitalares, bem como prestar serviços de assistência médico-hospitalar e laboratorial à comunidade, no âmbito do SUS (Brasil, 2010b). Sob a justificativa de maior autonomia no uso dos recursos, legalização dos contratos de trabalho e aprimoramento do processo de gestão das instituições de ensino e saúde, o governo Lula se despede de seu mandato, deixando a herança das Fundações Estatais de Direito Privado, ainda que sob nova roupagem: a EBSERH. Após a rejeição da MP n. 520 no Senado, em 2011, a então presidente da República, por meio da Lei n. 12.550, autoriza a criação da EBSERH, empresa com personalidade jurídica de direito privado e patrimônio próprio.

Sob o discurso da ineficiência da gestão pública e o alto custo dos hospitais 
federais, decorrentes da burocracia da legislação brasileira, a EBSERH é apontada pelo governo como "única" solução e tem ganhado espaço e adesão junto às universidades federais. Como aponta Granemann (2007), as saídas são nossas velhas conhecidas desde o início dos anos 1990: "soluções" gerenciais e administrativas para um problema social.

Contudo, torna-se necessário conhecimento e profunda reflexão acerca dessa alternativa de gestão, pois não é difícil compreender que os conflitos existentes em torno da gestão dos HUFs é também reflexo da não efetivação plena do SUS, conforme elaborado e defendido pelo movimento da Reforma Sanitária a partir de um embate de forças nas décadas de 1970 e 80 .

Importa ressaltar que apesar de avanços conquistados com a promulgação das Leis ns. 8.080/90 e 8.142/90 - que determinam como diretrizes o controle social, a universalização, a equidade e a integralidade da saúde - , permanece, na prática, ideais do projeto político direcionado a uma política de saúde que atenda interesses de mercado.

O custo de manutenção de um hospital público é caro, sabemos disso. A relação que empurra os hospitais universitários, ora para o Ministério da Saúde, ora para o Ministério da Educação, gera o descaso com esses hospitais de ensino que não possuem seu "pertencimento" definido nas políticas públicas. Sabemos, pois, que se trata de um jogo político velho quando não se quer priorizar uma instituição: o Estado a coloca como "filho sem pai", sem pertencimento a lugar algum. E quem perde com isso é o usuário do SUS (que não encontra o serviço na busca por acesso), o trabalhador da saúde (que vive a incerteza de sempre ser surpreendido por discursos gerenciais considerados "modernos" e que nada resolvem) e o controle social (que se perde com informações fragmentadas emitidas pelo Estado).

A EBSERH se enquadra dentro de mais um discurso gerencial industrial que fará a modernização da gestão dos recursos humanos. Primeiro são privatizados equipamentos, exames e terceirizada a contratação de pessoas - considerado o primeiro passo da privatização direta. $\mathrm{O}$ segundo passo foi a ameaça de entrega da gestão para uma organização social (OS) ou fundações - mas não foi firmado acordo pois as negociações do estado com a sociedade não foram favoráveis. Por último, o governo deu um passo atrás. Optou por uma privatização lenta, menos aguerrida e mais tímida para evitar abrir um diálogo com a sociedade: a criação de uma empresa pública de direito privado (EBSERH).

Temos certeza que a questão da gestão dos recursos humanos e dos acordos salariais seriam com certeza resolvidos se o Estado assim se propusesse a resolver publicamente os impasses da gestão dos hospitais universitários. No entanto, o caminho escolhido pelo Estado não foi esse. Optou-se por entregar a "chave do cofre" (gestão) e também os profissionais de saúde (recursos humanos) a uma empresa com mais um discurso gerencial "modernizador". 
Muitas dúvidas hoje perpassam o imaginário de vários profissionais de saúde que pertencem a esses hospitais com seus vínculos empregatícios sob dúvida. Por isso pretendemos que este artigo seja a abertura de um diálogo com estes profissionais de saúde hoje envolvidos neste momento de incerteza. Pensamos elementos por meio de questões e fomos em busca possíveis respostas para fomentar o debate sobre a situação dos hospitais universitários federais e a sua "entrega" a uma empresa pública de direito privado.

\section{Questões iniciais para o debate sobre a EBSERH: implicações legais e o discurso de modernização da gestão dos hospitais universitários}

Primeiramente, cabe distinguir que a Empresa Brasileira de Serviços Hospitalares (EBSERH) não se trata da mesma forma de administração jurídica que as organizações sociais (OSs) ou as fundações estatais do ponto de vista da gestão. A Empresa Brasileira de Serviços Hospitalares e a Fundação Estatal de Direito Privado são entes integrantes da administração pública indireta e, portanto, entes estatais. As organizações sociais são pessoas jurídicas de direito privado sem fins lucrativos, qualificadas como tal, para fins de celebrar contratos de gestão que tem por objeto a execução de serviços públicos de saúde, seja em equipamentos próprios, seja em equipamentos estatais.
Nas empresas (como o caso da EBSERH) e fundações estatais, a gestão continua a ser pública. O regime jurídico é que passa a ser híbrido. No caso das OSs, a gestão é privada, com regime jurídico privado permeado por algumas derrogações de direito público.

Do ponto de vista daqueles que querem garantir o SUS universal e equânime, o segundo ponto de análise refere-se à garantia de um sistema que seja realmente público e se a EBSERH não representaria uma forma velada de privatização.

[...] privatização, em sentido amplo é um conceito que abrange todas as formas pelas quais se busca uma diminuição do tamanho do Estado, podendo abranger a desregulamentação (diminuição da intervenção do Estado no domínio econômico), a desmonopolização de atividades econômicas, a privatização de serviços públicos (quando a atividade deixa de ser serviço público e volta à iniciativa privada), a concessão de serviços públicos (dada a empresa privada e não mais a empresa estatal) e as contratações de terceiros (contracting out), em que a administração pública celebra ajustes de variados tipos para buscar a colaboração com o setor privado, como os contratos de obras e prestação de serviços (a título de terceirização), os convênios, os contratos de gestão, os termos de parceria. (Di Pietro, 2011, p. 213)

A EBSERH é um ente estatal integrante da administração indireta. Não pode, portanto, ser considerada uma "privatização" em sentido técnico, porque não 
implica delegação de serviços, tampouco a desconstituição da natureza de serviço público dos serviços do SUS prestados em suas dependências. Na EBSERH mantém-se a vinculação orgânica do ente estatal com o poder público.

Entretanto, o modelo EBSERH, quando comparado aos modelos estatais clássicos de prestação de serviços públicos de saúde (autarquias e fundações públicas), implica uma escolha legislativa pela relativização das normas de direito público, flexibilizando-as.

A figura das empresas públicas surgiu classicamente visando à intervenção estatal econômica e, portanto, foi chamada por autores alemães como Der Staat Unternehmer (Meirelles, 2010, p. 405), que significa "o Estado na qualidade de empresário".

Como diz Meirelles, a empresa pública é uma figura ambivalente, que pertence ao mesmo tempo ao domínio do público e do privado. Por isso, embora a EBSERH não possa ser considerada um mecanismo de privatização propriamente dito, implica em ampliar o espectro de penetração da lógica do mercado na gestão dos serviços do Sistema Único de Saúde.

Esse é um modelo de gestão bastante utilizado pelas políticas econômicas desenvolvimentistas, aquelas em que o Estado assume o papel de ser um "Estado-empresa", capturando os valores que se hospedam na reprodução social. Ou seja: visão de gestão mercadológica para reger as políticas sociais.

Para melhor refletir sobre isso, um caminho encontrado é o do financiamento dessa empresa pública de direito privado. A EBSERH, assim como as empresas públicas de modo geral, pode vir a ser uma empresa estatal dependente ou não. A estatal dependente é a empresa controlada que recebe do ente controlador recursos financeiros para pagamento de despesas com pessoal ou de custeio em geral ou de capital, excluídos, no último caso, aqueles provenientes de aumento de participação acionária (art. $2^{\circ}$, inciso III, da Lei Complementar n. 101/2000 — Lei de Responsabilidade Fiscal [Brasil, 2000]). Nesse caso, a EBSERH receberá custeio orçamentário direto do poder público.

As empresas estatais não dependentes são aquelas que não dependem de financiamento direto do ente público controlador. A Lei n. 12.550/2011 — que cria a EBSERH - previu, em seu artigo $6^{\circ}$, a possibilidade de que a EBSERH formalize contrato com as instituições de ensino e com o próprio Sistema Único de Saúde para a prestação de seus serviços (Brasil, 2011). Tal previsão traz consigo a possibilidade de que a EBSERH se torne não dependente, ou seja, financiada pelos valores oriundos da relação contratual (no caso do SUS e do Ministério da Educação), e não do orçamento direto da administração pública. Provavelmente, os contratos que tenham por objeto a prestação de serviços de saúde serão firmados com a gestão estadual. Em um ou outro caso, os recursos são oriundos dos cofres públicos, mas sob mecanismos diversos.

As empresas estatais podem ter duas ordens de objetos: a prestação de serviços públicos ou a execução de atividade 
econômica de interesse público (Meirelles, 2010, p. 399). No primeiro caso, a utilização de empresas públicas para a prestação de serviços públicos tem sido classicamente voltada para os serviços remunerados que, embora públicos, não são gratuitos (saneamento básico, estradas, construção de casas populares etc.).

Entretanto, a Lei federal n. 12.550/2011, em seu artigo $3^{\circ}, \S 1^{\circ}$, restringe a serviços gratuitos e do SUS o objeto da prestação de serviços hospitalares pela EBSERH, o que a princípio nega a possibilidade de prestação paralela de serviços privados (Brasil, 2011).

Em alguns hospitais universitários do Brasil os servidores públicos, trabalhadores da saúde, começaram a ser "sondados" sobre a sua vinculação com a EBSERH, o que sugere que esses servidores seriam "cedidos" na sua forma de contratação à empresa. Pela disposição da Lei n. 12.550/2011 (Brasil, 2011) os servidores públicos vinculados ao hospital universitário "poderão", sim, ser cedidos à EBSERH. A lei não garante de forma categórica a referida cessão, abrindo brechas a outras possibilidades que não estão relacionadas taxativamente. Na hipótese de haver cessão, isso significa que o vínculo funcional do servidor público se mantém com o ente público federal e é mantida também a vinculação ao regime jurídico estatutário, com suas decorrências.

Todavia, isso geraria outro problema, talvez o mais agravante do ponto de vista da gestão dos serviços públicos. $\mathrm{O}$ artigo $7^{\circ}$ da Lei n. 12.550/2011 prevê que os servidores efetivos da instituição de ensino poderão ser cedidos à EBSERH, garantidas as vantagens do órgão de origem (Brasil, 2011). O salário dos servidores efetivos não será, portanto, alterado, e continuarão sendo pagos pelo MEC. Cabe destacar que, atualmente, não há nada pactuado sobre isso e, portanto, não temos garantia se essa transição acontecerá. O regime de pessoal da EBSERH é de emprego público. Também não há nenhuma garantia de paridade remuneratória entre os servidores efetivos cedidos e os empregados da EBSERH. Isto quer dizer que será possível a convivência de trabalhadores com variados tipos de contratação e salários em um mesmo hospital, o implique a fragilização das forças na luta de classes.

A lei federal é omissa quanto à cessão dos trabalhadores terceirizados (contratos temporários) que atuam na entidade absorvida pela EBSERH. Não há, portanto, garantia de manutenção ou renovação de seus contratos, o que de regra é próprio da precariedade jurídica desses instrumentos. Mas há previsão de contratos temporários para garantir a execução dos serviços enquanto não for realizado concurso para empregados públicos da EBSERH. Ou seja, podem conviver as três formas de contratação num primeiro momento. Mas a proposta é que essa convivência seja temporária, extinguindo-se os contratos temporários com a realização do concurso de empregados públicos e com a gradativa redução dos quadros efetivos, por aposentadoria ou outros fatores. Isto porque certamente não haverá a renovação desses quadros. 
Como empresa pública de direito privado, a EBSERH pode, sim, "acumular lucro". Mesmo quando voltados à execução de serviços públicos, as empresas públicas admitem lucro, embora não seja esse o seu objetivo principal e haja determinação da Lei n. 12.550/2011 no sentido de que os lucros obtidos sejam aplicados no seu próprio objeto. Outro fator interessante é que há uma dispensa legal de licitação para a EBSERH ser contratada pelo SUS e pelas instituições de ensino. Não há problema em tal dispensa porque se trata de uma relação entre entes públicos. Por outro lado, as compras de bens e serviços pela EBSERH devem ser realizadas com respeito à licitação, porque se trata de uma entidade da administração pública indireta, prestadora de serviço público, conforme o artigo 119 da Lei n. 8.666/93 (Brasil, 1993).

Deposita-se na EBSERH uma expectativa que se resume a solucionar todos os problemas de gestão dos hospitais universitários - principalmente voltados para a insuficiência de recursos. Não podemos esquecer que o problema na gestão de recursos humanos numa instituição vinculada à administração pública passa não apenas pela escolha do regime jurídico de pessoal, mas também pela diligência dos gestores em garantir-lhe efetividade.

Nesse cenário, questiona-se então onde seria o lugar do ensino e da pesquisa em saúde nessa relação empresa/universidade. Seria da mesma forma que hoje acontece? Será que conseguiríamos manter a autonomia da universidade nesse processo de construção do conhecimento?
A conformação constitucional implica que o SUS deve ter seus serviços prestados por entidades da administração pública, e os modelos constitucionais voltados para a prestação dos serviços de saúde pública são aqueles submetidos integralmente ao regime jurídico de direito público. São eles: as autarquias, as fundações públicas e os consórcios de direito público. Entretanto, a delegação dos serviços de saúde é admitida, desde que respeitadas as balizas legais. A escolha por um modelo permeado pelo regime privado não é, portanto, um imperativo, mas uma exceção permitida. Trata-se de uma escolha política pela exceção.

$\mathrm{O}$ artigo $6^{\circ}$ da Lei n. 12.550/2011 estabelece o necessário respeito à autonomia universitária, o que parece significar que a gestão das pesquisas não deve sofrer ingerências da EBSEHR (Brasil, 2011). Entretanto, trata-se de um novo modelo, e a interpretação do alcance de suas competências ainda será objeto de muito debate. Não é possível realizar previsões inequívocas sobre como vai se dar, na práxis, a relação entre a EBSERH e as instituições de ensino. Ademais, a prestação desses serviços será balizada por uma relação contratual, o que implica a possibilidade de negociações nesse sentido.

A lei prevê que a administração da EBSERH será realizada por um conselho de administração e não mais pela figura do gestor superintendente dos hospitais universitários. Isto muda toda a forma de hierarquização do poder decisório dentro da instituição e também as formas de participação social. Os conselhos de saúde, 
por exemplo, são colegiados permanentes que visam efetivar a participação da comunidade no SUS. São incumbidos de traçar diretrizes para a política de saúde, que devem ser respeitadas pelos gestores, como decorrência de um princípio democrático. A decisão política sobre a escolha do modelo de gestão de serviços SUS é sem dúvida uma diretriz a ser definida pela instância da participação popular. Não obstante, as políticas de saúde têm desconsiderado as decisões do controle social repetidamente, o que põe em dúvida a eficácia de uma eventual contestação dos conselhos de saúde a modelos de gestão.

\section{Considerações finais}

A garantia de funcionamento pleno dos hospitais universitários perpassa uma série de questões da administração dos serviços públicos, a manutenção do SUS universal sonhado pela Reforma Sanitária brasileira e a garantia do ensino, da pesquisa e da extensão aos graduandos e pós-graduandos das universidades públicas brasileiras.

Durante a elaboração deste artigo, nos perguntamos várias vezes qual a garantia que temos de não sermos surpreendidos em um futuro próximo se um aluno em fase de aprendizado técnico ser mais cobrado por economizar materiais durante o seu aprendizado do que a preocupação com o usuário que está sendo atendido. Isto é, se o discurso gerencial da economia de mercado irá se sobrepor à primazia do ensino.
Não temos nenhuma garantia de mais autonomia administrativa ao hospital universitário. Da mesma forma, nos questionamos: se a empresa (EBSERH) é pública, por que a gestão administrativa atual dos hospitais universitários federais não resolveu a questão salarial e os métodos de gestão com o mesmo capital público? Por que entregar os HUFs a uma empresa de direito privado e com interesses de gestão de recursos humanos em formato mercadológico?

Os hospitais universitários vêm sendo "visitados" várias vezes, no período de dezembro de 2011 a setembro de 2012, por interessados na implantação da EBSERH, visando "conhecer" o hospital no qual a empresa almeja se implantar de forma definitiva. Mas por que isto ocorreu com a participação bastante limitada, tímida e distorcida dos profissionais de saúde que seriam alvo dessa suposta nova empresa de gestão de pessoas? Ou seja, a chegada da empresa acontece silenciosamente, com o propósito de gestar e gerir recursos humanos sem a participação daqueles que seriam por ela "geridos"? Um suposto "novo" método de gestão que chega silenciosamente, acordado em gabinetes e imposto como um "pacote pronto" pelo Estado, pode ser considerado "novo"? Pode ser considerado participativo? Pode ser considerado democrático? Pode ser considerado transparente?

Outra questão que nos intriga nesse discurso de transição é o fato que a EBSERH terá sede em Brasília e a realidade vivida nas diversas regiões do Brasil são as mais diferentes em seus aspectos culturais, 
sociais, econômicos, demográficos e perfis epidemiológicos. As ações da EBSERH serão descentralizadas? Ou serão mais uma junção de discursos gerenciais impostos de cima para baixo com metas padronizadas a serem cumpridas por profissionais de saúde?

A transição da gestão será vivenciada em 2013 nos hospitais universitários federais. E, sobre isso, temos mais perguntas que respostas. Exatamente isso que nos une em tantos questionamentos sobre essa transição silenciosa que julgamos ser mais um passo rumo à privatização dos serviços públicos e à precarização da gestão, dos salários e da organização dos processos de trabalho camuflados mimeticamente em um discurso de um suposto novo modelo gerencial.

Recebido em 18/1/2013

Aprovado em 11/3/2013

\section{Referências bibliográficas}

BRASIL. Lei n. 8.080, de 19 de setembro de 1990. Dispõe sobre as condições para a promoção, proteção e recuperação da saúde, a organização e o funcionamento dos serviços correspondentes e dá outras providências. Diário Oficial [da] República Federativa do Brasil, Brasília, 20 set. 1990. Disponível em: $<$ http://portal.saude.gov.br/portal/arquivos/pdf/ lei8080.pdf $>$. Acesso em: 5 set. 2012.

. Lei n. 8.666, de 21 de junho de 1993.

Regulamenta o art. 37, inciso XXI, da Constituição federal, institui normas para licitações e contratos da administração pública e dá outras providências. Diário Oficial [da] República Federativa do Brasil, Brasília, 22 jun. 1993. Disponível em: <http:/www.planalto.gov.br/ ccivil_03/leis/L8666cons.htm>. Acesso em: 23 set. 2012 .

. Lei Complementar n. 101, de 4 de maio de 2000. Estabelece normas de finanças públicas voltadas para a responsabilidade na gestão fiscal e dá outras providências. Diário Oficial [da] República Federativa do Brasil, Brasília, 5 maio 2000. Disponível em: $<$ http:// www.planalto.gov.br/ccivil_03/leis/LCP/ Lcp101.htm>. Acesso em: 20 set. 2012.

Secretaria de Educação Superior. Diretoria de Hospitais Universitários e Residências em Saúde. A articulação da graduação em saúde, dos hospitais de ensino e das residências em saúde. In: SEMINÁRIO NACIONAL DO PROGRAMA NACIONAL DE REORIENTAÇÃO DAFORMAÇÃO PROFISIONAL EM SAÚDE - PRÓ-SAÚDE II, 1., Brasília, 2009a. Disponível em: $<$ http://www. prosaude.org/noticias/PriSemProII/apresentacoes/ApresentacaoPro-Saude-DHR.pdf>. Acesso em: 24 jan. 2010.

Secretaria de Educação Superior. Diretoria de Hospitais Universitários e Residências em Saúde. Relatório REHUF — Programa Nacional de Reestruturação dos Hospitais Universitários Federais. Brasília, 2009b. Disponível em: <http:/www.adufrj.org.br/ observatorio/?p=196>. Acesso em: $12 \mathrm{fev}$. 2010 .

. Secretaria de Educação Superior. Diretoria de Hospitais Universitários e Residências em Saúde. Decreto n. 7.082, de 27 de janeiro de 2010. Institui o Programa Nacional de Reestruturação dos Hospitais Universitários Federais (REHUF). Brasília, 2010a. Disponível em: $<$ http://portal.mec.gov.br/index.php?option= 
com content $\&$ view $=$ article $\& i d=15639 \&$ Item id=1082>. Acesso em: 12 fev. 2010.

Medida Provisória n. 520, de 31 de dezembro de 2010. Autoriza o Poder Executivo a criar a empresa pública denominada Empresa Brasileira de Serviços Hospitalares S.A. EBSERH e dá outras providências. Diário Oficial [da] República Federativa do Brasil, Brasília, 2010b. Disponível em: <http://www. planalto.gov.br/ccivil_03/_ato2007-2010/2010/ mpv/520.htm>. Acesso em: 2 set. 2012.

Lei n. 12.550, de 15 de dezembro de 2011. Autoriza o Poder Executivo a criar a empresa pública denominada Empresa Brasileira de Serviços Hospitalares - EBSERH; acrescenta dispositivos ao Decreto-lei n. 2.848, de 7 de dezembro de 1940 - Código Penal; e dá outras providências. Diário Oficial [da] República Federativa do Brasil, Brasília, 16 dez. 2011. Disponível em: <http://www.planalto.gov.br/ccivil_03/Ato2011-2014/2011/Lei/ L12550.htm>. Acesso em: $1^{\circ}$ out. 2012.

CARMO, M. Hospitais Universitários e integração ao Sistema Único de Saúde: estudo de caso: Hospital das Clínicas da UFMG — 1996 a 2004. Dissertação (Mestrado em Saúde Pública) - Faculdade de Medicina, Programa de Pós-graduação em Saúde Pública da Universidade Federal de Minas Gerais, Belo Horizonte, 2006. $121 f$.

CECÍLIO, L. C. O. O desafio de qualificar o atendimento prestado pelos hospitais públicos. In: MERHY, E. E.; ONOCKO, R. (Orgs.). Agir em saúde: um desafio para o público. São Paulo: Hucitec, 2002. p. 293-319.

CISLAGHI, J. F. Hospitais universitários: presente caótico e futuro incerto, 2010. Disponível em: <http://www.apufpr.org.br/artigos/ hus.pdf>. Acesso em: 22 nov. 2010.

DI PIETRO, M. S. Z. Parcerias na administração pública: concessão, permissão, franquia, terceirização, parceria público-privada e outras formas. 8. ed. São Paulo: Atlas, 2011.

DRAGO, L. M. B. "Servindo a dois senhores": a gestão do Hucam entre o ensino e a assistência. Dissertação (Mestrado em Política Social) - Universidade Federal do Espírito Santo, Programa de Pós-graduação em Política Social, Vitória, 2011. 210f.

GRANEMANN, S. Conferência Nacional de Saúde rejeita fundações estatais. Jornal da Adufrj. Rio de Janeiro, out. 2007. Disponível em: $<$ http://www.adufrj.org.br/observatorio/wp-content/uploads/2009/08/Confer\%C3\%AAncia-Nacional-de-sa $\% \mathrm{C} 3 \%$ BAde-rejeita-as-Funda $\% \mathrm{C} 3 \% \mathrm{~A} 7 \% \mathrm{C} 3 \% \mathrm{~B} 5$ es-Estatais-26_11_07.pdf>. Acesso em: 31 jan. 2011.

LIMA, L. P. O desafio gerencial da multiinstitucionalidade dos hospitais universitários: o caso do hospital das clínicas da Universidade Federal de Pernambuco. Tese (Doutorado em Saúde Coletiva) - Faculdade de Ciências Médicas, Programa de Pós-graduação em Saúde Coletiva da Universidade Estadual de Campinas, Campinas, 2004. 325f.

LITTIKE, D. Improvisando a gestão por meio da gestão do improviso: o processo de trabalho dos gestores de um hospital universitário Federal. Dissertação (Mestrado em Saúde Coletiva) - Universidade Federal do Espírito Santo, Programa de Pós-graduação em Saúde Coletiva, Vitória, 2012. 182f.

LOPEZ, E. A politica hospitalar brasileira. Rio de Janeiro, 2005. Disponível em: $<\mathrm{http} / /$ www.ensp.fiocruz.br/biblioteca/dados/Aul\%20 ELAINE\%20LOPEZ.ppt>. Acesso em: 27 jan. 2010.

MACHADO, M. H. Trabalhadores da saúde e sua trajetória na reforma sanitária. In: LIMA, N. T. et al. (Orgs.). Saúde e democracia: história e perspectivas do SUS. Rio de Janeiro: Fiocruz, 2005. p. 257-84. 
MÉDICI, A. C. Hospitais universitários: passado, presente e futuro. Trabalho realizado no Banco Interamericano de Desenvolvimento, Washington, D. C. Rev. Ass. Méd. Bras., São Paulo, v. 47, n. 2, p. 149-56, 2001. Disponível em: <http:// www.scielo.br>. Acesso em: 24 jan. 2010.

MEIRELLES, H. L. Direito administrativo brasileiro. 37. ed. São Paulo: Malheiros, 2010.

MONTAÑO, C. Terceiro setor e questão social: crítica ao padrão emergente de intervenção social. São Paulo: Cortez, 2002.

PILOTTO, B. Os hospitais universitários e sua crise. Disponível em: < http://www.scribd.com/ doc/36023434/Os-Hospitais-Universitarios-e-Sua-Crise>. Acesso em: 13 dez. 2010.

REIS, A. A. C.; CECÍLIO, L. C. O. A política de reestruturação dos hospitais de ensino: notas preliminares sobre os seus impactos na micropolítica da organização hospitalar. Saúde em Debate [on-line], v. 33, n. 81, p. 88-97, jan./ abr. 2009.

RIBEIRO, D. B. et al. Reflexões sobre demandas atendidas pelo serviço social no Núcleo de Atenção à Saúde do Trabalhador. In: ENCONTRO NACIONAL DE POLÍTICA SOCIAL, 5., Anais..., 2010, Vitória: PPGPS, 2010. [CD-Anais, Mundo do Trabalho, Daniela Borges Ribeiro 2.]

SILVA, A. L. A. Produção da subjetividade e gestão em saúde: cartografias da gerência. Tese (Doutorado em Saúde Coletiva) — Faculdade de Ciências Médicas, Programa de Pós-Graduação em Saúde Coletiva da Universidade Estadual de Campinas, Campinas, 2004. 214f. 